http://dx.doi.org/10.5007/1980-3532.2012n7p63

\title{
O Brasil e o capital-imperialismo, de Virgínia Fontes: breve comentário político
}

\author{
Iraldo Alberto Alves Matias \\ Doutorando em Sociologia (Universidade Estadual de Campinas - UNICAMP) \\ Professor do Instituto Federal de Santa Catarina (IFSC) \\ iraldom@gmail.com
}

FONTES, Virgínia. O Brasil e o capital-imperialismo: teoria e história. Rio de Janeiro: EPSJV/UFRJ, 2010. 370 p.

Originais recebidos em: 11/06/2012

Aceito para publicação em: 24/06/2012

O ano de 2010 pode ser considerado um marco para a retomada da discussão, no campo do anticapitalismo, acerca do desenvolvimento do capitalismo no Brasil, especificamente sobre suas práticas político-econômicas de natureza imperialista. Este fato se deve ao lançamento do livro O Brasil e o capital-imperialismo: teoria e história, da historiadora Virginia Fontes, professora e pesquisadora da Universidade Federal Fluminense, em uma parceria editorial entre a Fundação Oswaldo Cruz e a Universidade Federal do Rio de Janeiro.

Profunda conhecedora das contradições brasileiras em todas as suas dimensões, Virgínia Fontes merece reconhecimento por este lançamento por vários motivos. $\mathrm{O}$ primeiro, a sua simples publicação, principalmente em um cenário político marcado por um neokeynesianismo dissimulado. Isto representa um sinal de que setores da extremaesquerda brasileira, minoritários, é verdade, estão dispostos a enfrentar uma dura realidade política: o Brasil é uma nação imperialista. Pois é a partir da caracterização deste problema que devem ser traçadas estratégias de enfrentamento, na luta 
anticapitalista. Outro ponto importante: a retomada da discussão do caso brasileiro com enfoque na luta de classes, abordagem teórica que muitos apologetas vêm tentando enterrar, apesar de uma realidade cujos antagonismos sociais saltam aos olhos dos mais incautos "pós-modernos".

A obra apresenta pontos altos, como a crítica às novas ideologias individualistas, como o empreendedorismo (p.290); às práticas ambíguas do chamado terceiro setor (p.190) e das $O N G$ 's (p.231); além da discussão acerca da relação capital-ciência-saúde (p.60). Importante também é a critica da autora ao conceito de "neoliberalismo", por ser geralmente contrastado com o período anterior, do Welfare State (keynesianismo), diluindo o caráter capital-imperialista de ambos períodos (p.154). A denúncia do caráter fragmentador da organização política dos trabalhadores levada a cabo pelo multiculturalismo, por manter-se no "estrito terreno da defesa de uma etnia ou cultura especifica" (p.182), é igualmente crucial.

No entanto, não se trata de uma obra inquestionável. Tampouco, livre de contradições tanto em algumas de suas premissas, como em suas conclusões. Nesta concisa apresentação, o esforço se concentra em extrair uma análise política de 370 densas páginas, que abordam os mais variados e polêmicos temas, assumindo o risco de incorrer em alguma simplificação, mas sem resvalar para leviandades. $O$ Brasil e o capital-imperialismo... é uma compilação de material já publicado pela autora, em meios editoriais diversos, mas revisados no sentido de estabelecer um fio condutor entre diversas problemáticas abordadas em diferentes momentos.

$\mathrm{Na}$ busca por encontrar uma frase que representasse o espírito da obra aqui resenhada, a seguinte passagem parece bastante fidedigna: “O capital-imperialismo é devastador, mas envolve na atualidade o conjunto da existência humana" (grifei, p.152). É este drama que se encontrará ao longo dos sete capítulos que compõem a obra. $\mathrm{Na}$ linha do marxismo ortodoxo, o livro trata do processo de "luta pelo acesso de países retardatários (e de suas burguesias) à condição de países capital-imperialistas", seguindo a tese de que "esse caminho capital-imperialista subalterno vem sendo trilhado pelo Brasil contemporâneo" (p.14).

No primeiro capítulo, o conceito de expropriações é o centro da discussão, que perpassa todo o livro, onde a autora revisa o conceito estabelecendo um diálogo crítico com autores como Harvey, Wood, Quijano, Wallerstein, Rosa Luxemburg, Kautsky, entre outros. Ali, o leitor também encontrará uma ampla discussão sobre as relações entre o capital produtivo e o capital financeiro, fundamentada no pensamento de Marx. 
Fontes critica o mito "financeirista" atual e conclui enfaticamente: "o juro é uma cotaparte do mais-valor, é uma parcela do mais-valor!” (p.29).

No capítulo 2 é realizada uma revisão do conceito de imperialismo na ótica de Lênin e Gramsci, evidenciando o que seria a "atualidade" presente nestes autores. No capítulo subsequente, o centro da análise é o próprio conceito de capital-imperialismo, que seria uma síntese do conceito de imperialismo em Lênin, somado à análise gramsciana sobre hegemonia e luta de classes. Nos capítulos 4 e 5, a historiadora fluminense apresenta uma incursão pela história do Brasil, evidenciando a repressão do Estado brasileiro às lutas populares, num quadro de disseminação das expropriações e de "apassivamento da classe trabalhadora" (p.15). Como continuidade do debate exposto no capítulo anterior, o sexto demonstra a intensificação das expropriações no Brasil. Por fim, o sétimo capítulo encerra a jornada com um tributo/polêmica com seu mentor intelectual e político, Ruy Mauro Marini, e sua Teoria da Dependência e do subimperialismo brasileiro.

Fontes inicia com uma indagação: a perene crise social vivida no Brasil é fruto de uma "crise do capitalismo", ou é o solo por onde "se expandem" as relações capitalistas? A autora apresenta uma possível resposta para esta questão, que configura a sua hipótese de trabalho: “A crise social aguça e exacerba contradições que podem impulsionar a luta contra o capitalismo; porém, também suscita contratendências procurando ofuscar e impedir tais lutas", e continua, "para tanto, as burguesias - ainda que subalternas - precisam expandir suas formas de encapsulamento dos trabalhadores, ao mesmo tempo em que expandem suas fontes de extração de mais-valor" (p.11). Segundo Fontes, "a expropriação massiva é, portanto, condição social inicial, meio e resultado da exploração capitalista" (grifado no original, p.22).

Fontes realiza uma interessante apropriação da discussão sobre a acumulação primitiva do capital. Para a autora, não se trata de um fenômeno "episódico", mas de um constante processo de separação dos trabalhadores das condições sociais de produção (p.42). Lucidamente, critica a interpretação onde a acumulação primitiva é apresentada como algo que ocorreu no início do capitalismo. Por outro lado, Fontes acaba usando estes argumentos para colocar em questão o conceito de subsunção real, afirmando que este só pode ser entendido nos marcos por ela postos à prova.

Questionar a subsunção real nestes termos parece problemático, pois se trata de um conceito que explica justamente o processo de produção/apropriação de mais-valia relativa, através do desenvolvimento técnico-científico aplicado à produção. Isto 
significa a ampliação da composição orgânica do capital, isto é, o avanço do capital fixo sobre o variável, do trabalho morto sobre o trabalho vivo, com a ampliação da produtividade do trabalho por meio de maquinaria. Sobrepor o conceito de expropriação ao de subsunção real pode levar a uma não-diferenciação entre as formas mais arcaicas e as mais avançadas de capitalismo, portanto, entre a extração de mais-valia absoluta e relativa. ${ }^{1}$ No conceito de expropriação esse processo fica de certa forma obscurecido.

Neste momento, Fontes divide o conceito em expropriação primária (camponeses atraídos pelas cidades, ou expulsos do campo); e expropriação secundária (o capital-imperialismo contemporâneo). Quanto ao primeiro caso, a historiadora entra novamente em contradição, pois, ao explicar a expansão global das relações capitalistas, favorece uma idealização do "mundo rural" pré-capitalista ao afirmar que, até o início do século XX, "a grande maioria da população do planeta vivia no mundo rural e controlava em grande parte seus recursos diretos de existência" (p.13). A suposta autonomia produtiva do camponês já foi questionada na literatura científica sobre a questão agrária, não restando espaço para buscar no campo relações sociais de produção livres das coerções do mercado e da produção capitalista.

Se existem problemas na definição da autora acerca das expropriações primárias, os mesmos se ampliam quando passamos à esfera das expropriações secundárias que, de acordo com Fontes, incidem sobre "trabalhadores já de longa data urbanizados" (p.54). A crítica da autora ao neokeynesianismo fica comprometida quando discorre sobre o processo de "expropriação de direitos", associado ao projeto "neoliberal". Esse problema surge no quadro do atual "domínio completo da ideologia jurídica burguesa inclusive no interior dos movimentos de massa e das organizações de esquerda" (NAVES, 2009, p.01). Ainda que seja melhor "ter direitos" do que "perdêlos", isso ocorre dentro dos marcos da institucionalidade burguesa. Em momentos de abundância, o capital consegue com maior ou menor facilidade absorver certas demandas das lutas sociais, assim como, nas crises, não hesita em "expropriá-los".

Outro ponto delicado quanto às expropriações secundárias, diz respeito ao enquadramento do processo de privatizações. Para Fontes, as mesmas "incidiram sobre bens coletivos, similares às terras comunais" (p.60). Sem duvidar do processo nefasto que impulsionou as privatizações no Brasil, principalmente nos serviços básicos (educação, saúde, previdência, etc.), associar propriedade estatal à noção de "bens

\footnotetext{
${ }^{1}$ Consultar Bernardo (2009).

Em Debat: Rev. Dig., ISSNe 1980-3532, Florianópolis, n. 7, p. 63-69, jan-jul, 2012.
} 
coletivos" demonstra a velha dificuldade da esquerda de se livrar da concepção jurisdicista, que entende socialismo como propriedade estatal sobre os meios de produção.

Algumas destas questões vão delinear uma problemática crucial na delimitação do campo político de qualquer autor: a definição da natureza social da União Soviética. Este talvez seja o tema mais nebuloso em $O$ Brasil e o capital-imperialismo..., pois a geopolítica soviética é constantemente ignorada, ou relativizada, na obra. Por exemplo, quando a autora descreve o período entre as duas Grandes Guerras, afirma que "a humanidade vivenciou enormes transformações históricas, a começar pela revolução de 1917 e, na virada da década de 1980 para 1990, sua derrocada” (p.113). Considerar o ano de 1989 como a "derrocada" da revolução russa, demonstra um hiato de cerca de 70 anos na compreensão da ascensão do capitalismo de Estado na URSS.

Essa indefinição analítica prossegue quando Fontes define a Guerra Fria pelo antagonismo entre "países pós-revolucionários" e "países capitalistas", no contexto da expansão capital-imperialista (p.149) ${ }^{2}$. Nesta passagem, o adjetivo "capitalista" define um conjunto de relações socias de produção. O mesmo não se pode dizer do termo "pósrevolucionário", que demarca apenas um momento específico na linha do tempo histórico. Fontes lança mão do conceito de "pós-capitalismo", de Mészáros, e define a URSS como um “capitalismo de Estado pós-revolucionário", seguindo o que seriam as formulações de Lênin e Trotsky. É importante lembrar que Trotsky nunca aceitou que a URSS fosse definida como capitalismo de Estado, definindo-a como "Estado operário burocraticamente degenerado" "3. Com relação ao conceito de capitalismo de Estado em Lênin, é bastante controverso, tendo sido exaustivamente discutido por Bettelheim $(1976)^{4}$. No entanto, Fontes reconhece a burocratização das lutas sociais promovida pelos Partidos Comunistas, como no contexto do Maio de 68.

Adiante, Fontes discute o processo de industrialização de países como o Brasil a partir da Teoria da Dependência. Tais "processos industrializantes", afirma a autora, ocorreram "sob estreita dependência dos países centrais, subalternizando-se (voluntariamente) tais burguesias (e seus governos) a decisões forâneas (...)” (p.167).

\footnotetext{
${ }^{2}$ Para cobrir esta lacuna sobre o papel da URSS no imperialismo internacional, durante a Guerra Fria, ver Mattick (2010).

${ }^{3}$ Sobre este conceito, Trotsky afirma em 1940 que, "em relação à defesa da URSS contra o imperialismo, esta mesma definição era, em 1920, como hoje, inalteravelmente concreta, ao tornar obrigatória para os operários, a defesa do Estado em questão" (1987, p.144).

${ }^{4}$ Rosdolsky (2001) e Mattick (2010) demonstram como as concepções de Hilferding surgem como base teórica da ideologia do capitalismo de Estado. Lembrando que o conceito lenineano de imperialismo, com o qual opera Fontes, é totalmente fundamentado na análise econômica de Hilferding.
} 
Recupera este debate a partir de autores como Florestan Fernandes, mas, principalmente de Ruy Mauro Marini e seu conceito de subimperialismo, assente no "processo de exportação de capitais a partir do Brasil” (p.318). Ainda que Fontes problematize o pensamento de Marini, considerando que sua tese "não resolve a especificidade da subalternização da classe trabalhadora brasileira e da produção capitalista no Brasil" (p.355), não coloca em questão a própria Teoria da Dependência. Assim, a autora aprofunda as posições de seu mestre ao relacionar, por um lado, o desenvolvimento dependente do capitalismo brasileiro, com práticas imperialistas subalternas, por outro.

Portanto, a transposição teórica da luta de classes em âmbito internacional, para a luta entre nações ${ }^{5}$ - presente na análise da dominação do centro sobre a periferia -, é mantida. Justamente este ponto torna tão difícil a superação total da ideologia nacionalista, quando Fontes discute, por exemplo, o "bolivarianismo". Ao enxergar uma positividade no nacionalismo, devido ao seu suposto caráter "antiimperialista", considera que "não parece mais suficiente, embora ainda seja necessário, enfrentar o imperialismo no seu formato clássico, na luta pela independência Nacional” (p. 205206). Aqui, o risco é não perceber que o "nacionalismo antiimperialista" se limita a ser contrário meramente ao imperialismo dos outros, em defesa dos próprios interesses expansionistas.

A seguir, a autora analisa o crescimento das empresas transnacionais de origem brasileira, como Petrobras, Coteminas, Odebrecht, entre outras, mostrando sua atuação de natureza capital-imperialista em âmbito internacional. Como afirma a autora,

não se trata mais de mera exportação de produtos, mas da submissão de trabalhadores de outras nacionalidades à truculência característica da expansão burguesa brasileira, com o uso de milícias, informações privilegiadas, aplicando no exterior as práticas que aqui conhecemos (...) (p.339).

Ao final, Fontes alerta para os perigos de qualquer manifestação de nacionalismo, pois constitui uma barreira ao objetivo internacionalista de "opor-se de maneira decidida a todas as formas de capital-imperialismo" (p.351). Talvez esta seja a origem da dificuldade da esquerda brasileira digerir esta obra, o que a torna incontornável, para críticos e partidários de suas teses.

\footnotetext{
${ }^{5}$ Mattick (2010) demonstra que essa é a essência da caracterização do imperialismo por Lênin. Ver o desenvolvimento dessa discussão na profícua série de artigos Nunca antes na história deste país..., onde diversos autores defendem o caráter imperialista do Brasil, a partir de uma crítica à Teoria da Dependência.
}

Em Debat: Rev. Dig., ISSNe 1980-3532, Florianópolis, n. 7, p. 63-69, jan-jul, 2012. 


\section{Referências}

BERNARDO, João. Economia dos conflitos sociais. São Paulo: Expressão Popular, 2009.

BETTELHEIM, Charles. A luta de classes na União Soviética: primeiro período (19171923). Rio de Janeiro, Paz e Terra, 1976.

MATTICK, Paul. Marx \& Keynes: Os limites da Economia Mista. Lisba: Antígona, 2010.

NAVES, Márcio Bilharinho. Análise marxista e sociedade de transição. Campinas: IFCH/UNICAMP, 2005.

PASSA PALAVRA. Nunca antes na história desse país.. Disponível em

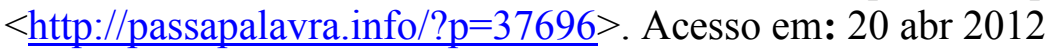

ROSDOLSKY, Roman. Gênese e estrutura de O capital de Karl Marx. Rio de Janeiro: EDUERJ/Contraponto, 2001.

TROTSKY, Leon. Em Defesa do Marxismo. São Paulo: Proposta Editorial, 1987. 